\title{
Socio-Economic Determinants of Hepatitis B \& C in Rural Poor of Pakistan
}

\author{
Sohail Kamran \\ Organization for Social Development Initiatives, Karachi, Pakistan
}

\begin{abstract}
Hepatitis B \& C have been identified the most common diseases in Matyari, Khairpur and Shikarpur districts of Sind and district Mardan KPK, Pakistan. Down the road more than 7,000 individuals have been catered effectively in a number of screening and vaccination campaigns, supported by the disease specific awareness and periodic workshops by involving all stakeholders. Data collected over the period of last 4 years suggests moderate to high prevalence of hepatitis B \& C in these districts that accounts for $4-6 \%$ of all health complaints. Less income opportunities, out of pocket expenses ( $67 \%$ of total expenditure on health care) and illiteracy has dragged the importance of health care to the bottom line on their priority list. Unsafe blood transfusions soiled drinking water and poor sanitation has turned the situation worse. Social behaviors are complex in rural communities and being a male dominating society men are supposed to be the bread earner and almost all the decisions are made by them. Females are mostly involved in domestic works and not freely allowed to go out to the health facilities for their routine checkups and can't take active participation in immunization campaigns. Mothers have less awareness regarding first line prevention of their children through common health and hygiene measures whereas general false believes and insecurities about the effects of different vaccines and medicines for secondary prevention made the situation vulnerable. Farming is the main source of livelihood in rural communities and demands more work. Due to old and traditional agricultural approaches farmers have to work from dawn to dusk to earn their livelihood that causes less interest of villagers in community development activities including health care prevention and practices and expose them to the vicious circle of health and poverty.
\end{abstract}

Key words: Socio economic determinants, hepatitis B \& C, rural areas of Pakistan.

\section{Abbreviations and Acronyms \\ CI Confidence Interval \\ KPK Khaibar Pakhtoon Khawah \\ OSDI Organization for social Development Initiatives \\ WHO World Health Organization}

\section{Introduction}

Hepatitis is a significant cause of worldwide morbidity and mortality especially high numbers are reported in Asia. About 3,500-4,000 million peoples are chronic carriers of Hepatitis B in which $75 \%$ of the population is from Asia and the western Pacific [1].

Pakistan carries a huge burden of both hepatitis B and $\mathrm{C}$ and approximately 7-9 million carriers of hepatitis B virus with a carrier rate of 3-5\% [2]. Health survey conducted by OSDI (Organization for Social Development Initiatives) in $2012-13$ pointed to

Corresponding author: Sohail Kamran, research field: public health. E-mail: drkamran@osdi.org. a high prevalence in OSDI focus communities. In general population prevalence of hepatitis $\mathrm{B}$ was reported approximately $2.5 \%$ and hepatitis $\mathrm{C} 4.9 \%$ that showed a cumulative figure of $7 \%$ with a burden of 12 million infected individuals WHO [3] factsheet reported that vaccination of peoples at potential risk, better sterilization technique for operative procedures, good personal health hygiene and safe practices are the best measures to prevent and control hepatitis.

\section{Methodology}

A descriptive/cross sectional study was done. The basic sampling unit was household which is defined as a unit consists of one or more people who live in the same dwelling and also share at meals or living accommodation [4]. Random sampling was done to estimate exposure with the sample size of 92 individuals. Correctly for the design outcome about 184 individual were identified. Sample range was set 
with high precision i.e. 240; 24 cluster with 10 individuals in each cluster. OSDI baseline survey questionnaire was used in the study and apart from socio-economic and demographic information some structured questions on general health awareness and practices, maternal knowledge about the disease and vaccination.

\section{Data Collection and Processing}

All the data was taken through prescribed questionnaire and showed moderate to high prevalence of hepatitis B \& $\mathrm{C}$ in these districts that accounts for $4-6 \%$ of all health complaints. In order to authenticate the data entry an intermediate rechecking of 25 percent of the entered data was evaluated on each day of data entry. The data retrieved from the survey study was utilized for estimates of vaccine exposure rendered by point estimates and their respective $95 \%$ confidence interval (CI) and to study the socio economic factors causing non-immunization. Administrative data was compared with the data obtained from point estimates of our survey study.

\section{Findings}

Survey results showed that hepatitis is the third most common diseases in OSDI's focus areas of Matyari, Khairpur and Shikarpur districts of Sind and Mardan KPK, Pakistan. This account for $4-6 \%$ of all health complaints registered at local health care facilities. Less income opportunities, out of pocket expenses (67\% of total expenditure on health care), illiteracy, lack of access \& availability of health care services

Table 1 Prevalence of Hepatitis B \& $\mathrm{C}$ in general population of Pakistan and high risk groups.

\begin{tabular}{llll}
\hline & Population Group & Prevalence of Hepatitis B\% & Prevalence of Hepatitis B\% \\
\hline 1 & General Population & 3 & 5.31 \\
2 & Injecting drug users & 22.8 & 12.18 \\
3 & Hemophilic/Thalassemia children & 6.25 & 24.7 \\
4 & Hemodialysis patients & 9.65 & 30.6 \\
5 & Sex workers & 11.65 & 15 \\
6 & Health care providers & 6.02 & 5.44 \\
\hline
\end{tabular}

Source: National Hepatitis Control Program, Ministry of Health Government of Pakistan, Islamabad.

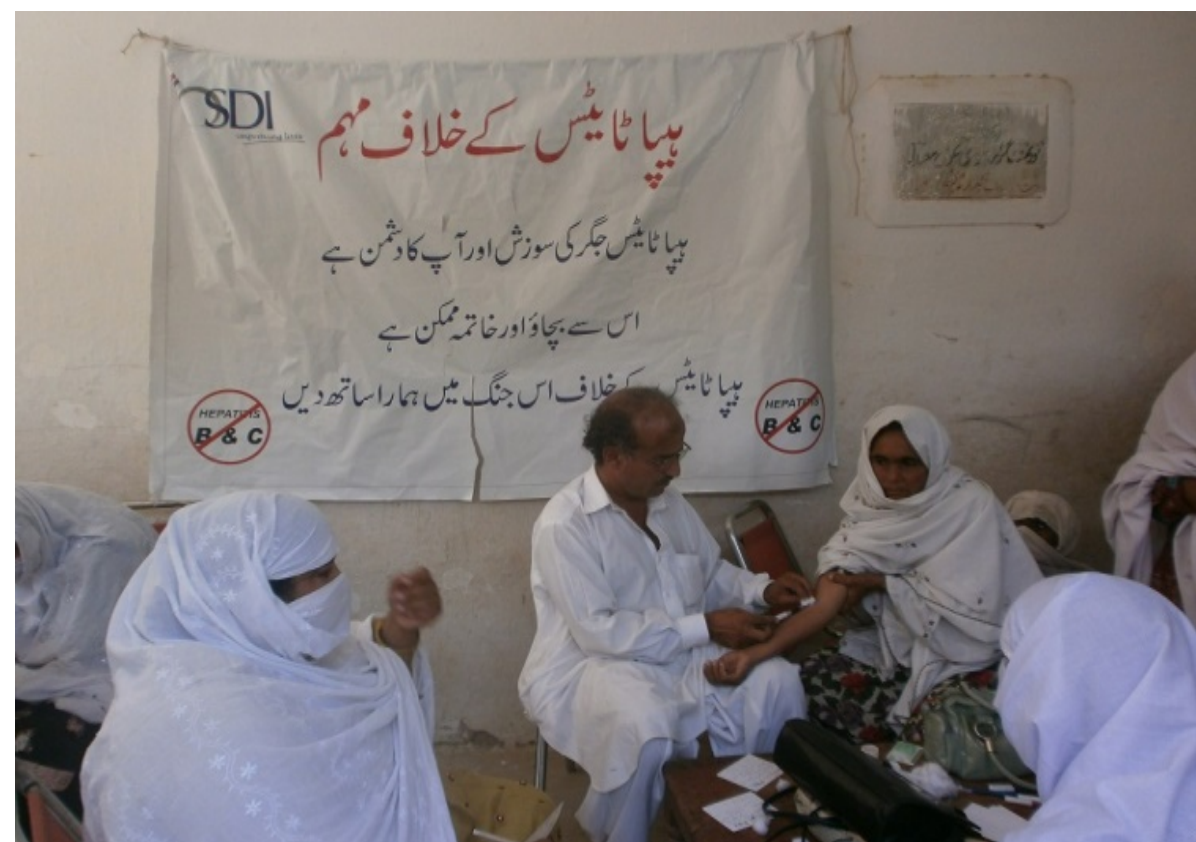

Fig. 1 Screening of hepatitis B \& $C$ in village Syedabad Mardan, KPK Pakistan.

Source: OSDI's Hepatitis prevention \& control Program, Mardan KPK, Pakistan. 
along with social and cultural taboos have been identified the major cause of hepatitis spread. The data explains availability of health services in these areas of Sindh but household still spends large part of the their income on health and looks like they are not attentive and cautious about their health status or they do not take this problem as priority. So, extensive awareness about preventive health and its importance should be promoted in this community.

\section{Added Value to the One Health Approach}

Improving lives of underprivileged through sustainable development initiatives and poverty alleviation are essential for long term solutions. And the lives that have been improved should have multiple layers of safety nets to protect them from any socio-economic shock in future.

\section{Conclusions}

Social behaviors are complex in rural communities of Pakistan. Despite the access and availability of hepatitis vaccines in remote areas its utilization and safe practices are less in the community due to common false believes against vaccines, social and cultural constraints. An integrated approach with extensive general and preventive health care awareness is essential to address the issue.

\section{References}

[1] Hou, J., Liu, Z., and Gu, F. 2005. "Epidemiology and Prevention of Hepatitis B Virus Infection."

[2] Ali, M., Idrees, M., Ali, L., Hussain, A., Rehman, I., Saleem, S., Afzal, S., and Butt, S. 2011. Hepatitis B virus in Pakistan: A systematic review of prevalence, risk factors, awareness status and genotypes.

[3] World Health organization 2014. Fact sheet.

[4] Haviland, W. A. 2003. Anthropology. Wadsworth: Belmont, CA.

[5] Khan, F., Shams, S., Qureshi, I. D., Israr, M., Khan, H., Sarwar, M. T., and Ilyas, M. 2011. Hepatitis B virus infection among different sex and age groups in Pakistani Punjab. 